Thus in normal subjects or patients with impaired renal function injection of $40 \mathrm{mg}$. of gentamicin fails in the majority of cases to produce serum levels reaching the minimum inhibitory concentration of clinical isolates of Ps. aeruginosa. With this dose the serum level will rarely exceed the minimum inhibitory concentration by a factor of two, nor will it be maintained for half the interval between doses, though both circumstances are desirable when treating pseudomonas infections.

Serum levels in patients with impaired renal function may gradually build up even on small doses, but this is an inefficient method of treatment calculated to encourage the development of resistance in a bacterial population. In three patients treated unsuccessfully the minimum inhibitory concentration of strains isolated after treatment had increased eightfold. This is the first report of resistance acquired in vivo, and it is interesting that there is a similar increase in the minimum inhibitory concentration of kanamycin, though naturally occurring resistance to kanamycin does not involve gentamicin.

Doses of $80 \mathrm{mg}$. produce more realistic peak levels $-5.4 \mu \mathrm{g} . /$ $\mathrm{ml}$. in one patient, and $10.15 \mu \mathrm{g} . / \mathrm{ml}$. in another in whom the dose was increased during treatment. If treatment with gentamicin is contemplated initial dosage of this order, or possibly even higher, seems necessary. To avoid toxic levels, estimation of serum concentrations is necessary in patients with impaired renal function and probably in the elderly (compare streptomycin). Prolonged courses of treatment are to be avoided. If given in adequate dosage initially treatment is likely to be effective, if it is to succeed at all, in 7 to 10 days.

It is assumed in this discussion that adequate tissue levels are necessary for effective treatment, as they clearly must be for any lesion outside the urinary tract. The concentrations attained in the urine are much higher, and may suffice to overcome a urinary tract infection not involving the renal parenchyma.

The work reported is being continued as a study of the relation of serum levels to results of treatment in urinary infections, complicated and uncomplicated.

\section{Summary}

Blood concentrations were assayed in normal subjects and in patients receiving the recommended dose of gentamicin. These were often found to be lower than the usual minimum inhibitory concentration of this antibiotic for Pseudomonas aeruginosa. The resistance of the infecting strain in three patients given this dose increased during treatment. It is suggested that larger doses, controlled by blood assay, are required for satisfactory therapeutic effects.

We would like to thank Professor L. P. Garrod for his encouragement in preparing this report and our clinical colleagues for allowing us to include reports of cases under their care.

The gentamicin sulphate used was supplied as Genticin by British Schering Limited.

\section{REFERENCES}

Barber, M., and Waterworth, P. M. (1966) Brit med F, 1, 203

Bulger, R.' J., Sidell, S., and Kirby, W. M. M. (1963). Ann. intern. Med., 59, 593 .

Jao, R. L., and Jackson, G. G. (1964). F. Amer. med. Ass., 189, 817.

Klein, J. O., Eickhoff, T. C., and Finland, M. (1964). Amer. F. med. Sci., 248, 528.

Mitchison, D. A., and Spicer, C. C. (1949). 7. gen. Microbiol., 3, 184.

Sweedler, D. R., Gravenkemper, C. F., Bulger, R. J., Brodie, J. L., and Kirby, W. M. M. (1963). Antimicrobial Agents and Chemotherapy, p. 157.

Weinstein, M. J., Luedemann, G. M., Oden, E. M., and Wagman, G. H. (1963). Ibid., p. 1

\title{
Parenteral Administration of Gentamicin in Renal Failure: Patients Undergoing Intermittent Haemodialysis
}

\author{
J. R. CURTIS,* M.B., M.R.C.P.; S. J. MCDONALD,* M.B., PH.D.; J. H. WESTON, † L.INST.BIOL.
}

Brit. med. F., 1967, 2, 537-539

Gentamicin is a broad-spectrum antibiotic chemically related to neomycin, kanamycin, and streptomycin (Rosselet et al., 1963 ; Weinstein et al., 1963 ; Barber and Waterworth, 1966). After parenteral administration, elimination is mainly via the kidney in normal subjects, $80-90 \%$ being recoverable in the active form in the urine; a small amount may be found in bile (Black et al., 1963). This study was undertaken to obtain information on blood levels of gentamicin and to assess what dosage revision may be necessary in severe renal failure.

\section{Methods}

Two normal subjects and three patients with terminal renal failure were studied. The patients were maintained on chronic intermittent haemodialysis. Gentamicin was administered therapeutically to two of the patients because of Pseudomonas pyocyanea shunt-site infections and prophylactically to the third. Details of the patients and normal subjects are given

\footnotetext{
- Lecturer in Medicine, Charing Cross Hospital Medical School, Fulham Hospital, London W.6.

+ Microbiologist, Nicholas Research Institute, Slough.
}

in the Table. The patients were dialysed for 14 hours twice weekly by means of a modified two-layer Kiil dialyser with cuprophane membranes (PT 150). Dialysis fluid at $40^{\circ} \mathrm{C}$. was employed in a single pass system (Curtis and de Wardener, 1967). In the Table the plasma creatinine concentration and creatinine clearance and blood urea figures for the three patients are those obtained immediately before beginning intermittent haemodialysis. In each study heparinized plasma samples were obtained before and at varying intervals up to 72 hours after the intravenous administration of $40-80 \mathrm{mg}$. of gentamicin. The

\begin{tabular}{|c|c|c|c|c|c|c|c|}
\hline \multirow[b]{3}{*}{ Subject } & tails of & Three Patients & and & Two & Normal & jects $S$ & lied \\
\hline & \multirow[b]{2}{*}{$\begin{array}{c}\text { Weight } \\
\text { (kg.) }\end{array}$} & \multirow[b]{2}{*}{ Diagnosis } & \multicolumn{2}{|c|}{ Gentamicin } & \multirow{2}{*}{$\begin{array}{c}\text { Plasma } \\
\text { Creatinine } \\
\text { (mg.l } \\
100 \mathrm{ml} .)\end{array}$} & \multirow[b]{2}{*}{$\begin{array}{l}\text { Creatinine } \\
\text { Clearance } \\
\text { (ml./min.) }\end{array}$} & \multirow{2}{*}{$\begin{array}{c}\text { Blood } \\
\text { Urea } \\
\text { (mg./. } \\
100 \mathrm{ml} .)\end{array}$} \\
\hline & & & $\begin{array}{l}\text { Total } \\
\text { Dose } \\
\text { (mg.) }\end{array}$ & $\left|\begin{array}{c}\text { Dura- } \\
\text { tion } \\
\text { (Days) }\end{array}\right|$ & & & \\
\hline Case 1 & 51 & $\begin{array}{l}\text { C.G.N. and } \\
\text { malignant }\end{array}$ & & & & & \\
\hline $\begin{array}{l}\text { A.B. } \\
\text { A.D. } \\
\text { C.D. }\end{array}$ & $\begin{array}{l}70 \\
42 \\
80 \\
55\end{array}$ & $\begin{array}{l}\text { hypertension } \\
\text { C.G.N. } \\
\text { Normal } \\
\text { "" }\end{array}$ & $\begin{array}{l}500 \\
170 \\
460 \\
=\end{array}$ & $\begin{array}{l}24 \\
10 \\
26 \\
=\end{array}$ & $\begin{array}{r}20.0 \\
11.9 \\
13.6 \\
0.8 \\
0.9\end{array}$ & $\begin{array}{r}1.0 \\
0.5 \\
0.4 \\
98.0 \\
101.0\end{array}$ & $\begin{array}{r}310 \\
305 \\
250 \\
30 \\
20\end{array}$ \\
\hline
\end{tabular}


intravenous route was chosen because all these patients were receiving warfarin. The plasma was separated from the red cells under sterile conditions and maintained at $4^{\circ} \mathrm{C}$. Gentamicin was assayed blindly by the zone of inhibition well technique employing Bacillus pumilus (N.C.T.C. 1959). This technique is sensitive to $0.05 \mu \mathrm{g}$. of gentamicin per ml.

\section{Results}

Plasma Concentration in Normal Subjects.-Ten minutes after the intravenous injection of $1.6 \mathrm{mg}$. of gentamicin per $\mathrm{kg}$. body weight to the two normal subjects the plasma concentration rose to 5 and $7.5 \mu \mathrm{g} . / \mathrm{ml}$. respectively. In both instances no antibiotic activity was detected in the plasma 24 hours after administration.

Plasma Concentration in Patients with Renal Failure.After the initial intravenous administration of $0.8 \mathrm{mg}$. of gentamicin per $\mathrm{kg}$. body weight to the three patients the mean plasma level at 10 minutes was $6 \mu \mathrm{g} . / \mathrm{ml}$., and 24 hours later it had fallen to $4.5 \mu \mathrm{g} . / \mathrm{ml}$. At 48 hours the mean level was 2.0 $\mu \mathrm{g} . / \mathrm{ml}$. On a second occasion, 72 hours later, $1.6 \mathrm{mg}$. of gentamicin per $\mathrm{kg}$. body weight was given intravenously. Before this injection the mean plasma concentration of gentamicin was $1.5 \mu \mathrm{g} . / \mathrm{ml}$. ; 10 minutes later it was $16.0 \mu \mathrm{g} . / \mathrm{ml}$., falling to $8.6 \mu \mathrm{g} . / \mathrm{ml}$. at 24 hours and to $6.5 \mu \mathrm{g} . / \mathrm{ml}$. at 48 hours (Fig. 1).

Effect of Haemodialysis on Plasma Gentamicin Disappearance Rates.-In the 16 to 27 hours preceding dialysis the level of gentamicin activity in the plasma fell by $0.07 \pm 0.04 \mu \mathrm{g} . / \mathrm{ml}$./ $\mathrm{hr}$., and during the 14-hour dialysis period by $0.28 \pm 0.06 \mu \mathrm{g}$./ $\mathrm{ml}$./hr. (Fig. 2). The difference in rate of disappearance is statistically significant $(P<0.001)$. This suggests that gentamicin is removed by haemodialysis. It is not possible to measure the amount of gentamicin removed during dialysis, since the dialysate effluent totals 4201 . during a 14-hour dialysis. The concentration of gentamicin in this volume is at the limit of sensitivity of the assay technique.

In-vitro Dialysis of Gentamicin from Plasma.-To determine whether gentamicin in plasma can be dialysed through a cuprophane membrane (PT 150) the following experiment was carried out. A Technicon AutoAnalyzer dialyser unit was set up with a PT 150 membrane. Reconstituted human plasma containing gentamicin and exogenous creatinine was placed in the sample compartment and dialysed against dialysis fluid in the recipient compartment. Both plasma and dialysate were maintained at $40^{\circ} \mathrm{C}$., and were recycled at the same rate by means of an AutoAnalyzer proportioning pump. Over the 14hour period of dialysis the concentration of gentamicin in the plasma fell from 20 to $12 \mu \mathrm{g} . / \mathrm{ml}$. while that in the dialysis fluid in the recipient compartment rose from zero to $6 \mu \mathrm{g}$./ ml. (Fig. 3).

\section{Discussion}

Gentamicin has a broad spectrum of activity and is therefore of potential value in many clinical situations. Since the drug is excreted largely unchanged in the urine it was to be expected that dosage would have to be adjusted in patients with renal failure. The toxic effects of gentamicin described in the literature so far consist of mild erythematous rashes, transient elevation of S.G.O.T. levels (Klein et al., 1964), moderate elevation of blood urea (Bulger et al., 1963), and vestibular dysfunction, the latter being the most frequently observed adverse reaction to the drug (Bulger et al., 1963; Jao and Jackson, 1963; Sweedler et al., 1963 ; Brayton and Louria, 1964). A total of only eight cases of vestibular damage have been reported; seven of them had renal failure, including one that was being treated by intermittent haemodialysis. In most of these patients dosage was in excess of that recommended by the manufacturers, but it is not clear from the literature whether toxicity is associated with serum concentration or total dosage. Two of our patients (Cases 1 and 3) had had plasma levels in excess of $10 \mu \mathrm{g} . / \mathrm{ml}$. on seven occasions for periods of up to 24 hours. On this regimen there has been no progressive accumulation of gentamicin in the plasma over a threc-weeks period and no toxic effects have occurred. However, the maximum total dosage (see Table) was only $500 \mathrm{mg}$. From the results presented here it would appear reasonable in patients being dialysed for 14 hours twice a week with a modified Kiil dialyser, cuprophane membranes (PT 150) being used to give $1 \mathrm{mg}$. of gentamicin per $\mathrm{kg}$. body weight at the end of each dialysis.

There is a notable difference between the peak plasma concentrations of gentamicin in the patients with chronic renal failure compared with the normal subjects. In the two normal subjects peak plasma levels of 5 and $7.5 \mu \mathrm{g} . / \mathrm{ml}$. were obtained 10 minutes after the intravenous injection of $1.6 \mathrm{mg}$. of gentamicin per kg. body weight ; whereas in the patients with chronic renal failure peak plasma levels of $16 \mu \mathrm{g} . / \mathrm{ml}$. were obtained. The control plasma obtained from the patients contained 0.1 to $2.5 \mu \mathrm{g}$. of gentamicin per ml. due to previous administration of the drug. There are at least two possible explanations for the higher peak plasma levels of gentamicin obtained in the patients with chronic renal failure. It is possible that the rate of equilibration of the gentamicin within its distribution volume is slower in the presence of renal failure. Secondly, the volume in which the gentamicin is distributed might be much smaller in the patients on intermittent haemodialysis than in normal subjects. The latter is unlikely, since it has been shown that both the plasma and extracellular fluid volumes are norma! in patients undergoing intermittent haemodialysis (E. S. Garnett, personal communication, 1965). Since most of the gentamicin injections are given at the end of dialysis, transient acute changes in body fluid spaces might occur as the result of ultra-

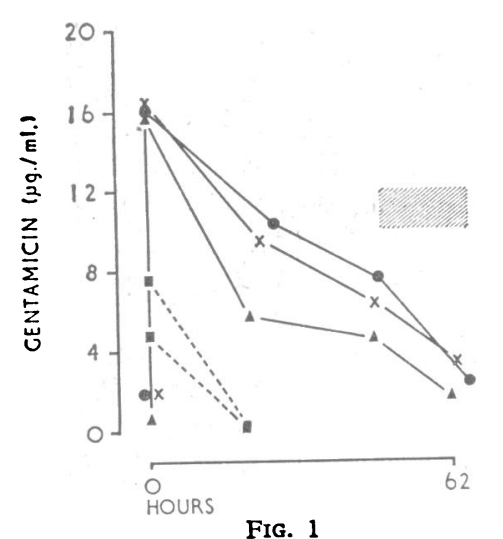

FIG. 1

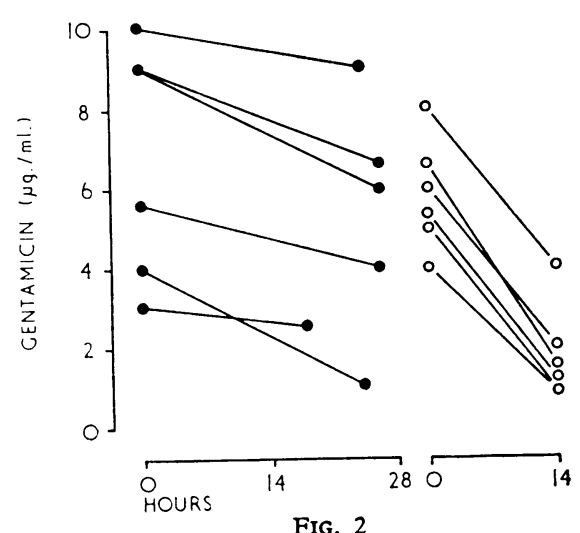

Fig. 2

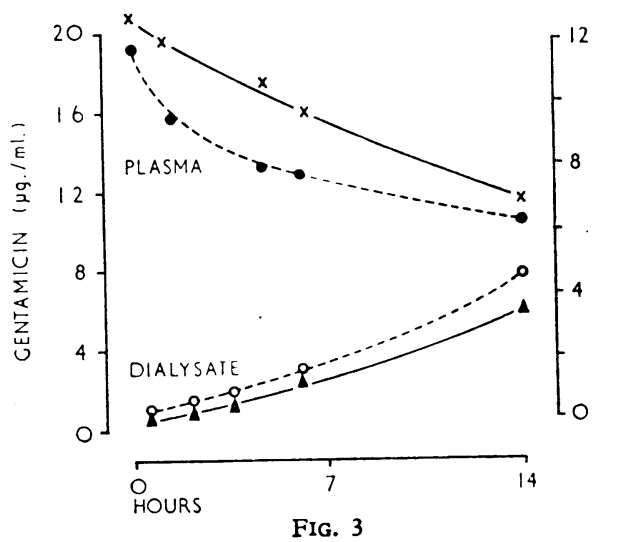

FIG. 3

Frg. 1.-Plasma concentration of gentamicin after intravenous administration of $1.6 \mathrm{mg}$. gentamicin $/ \mathrm{kg} . \mathrm{body}$ weight. Normal subjects. The cross-hatched area indicatcs the period of haemodialysis. Fig. 2. - Change in plasma gentamicin concentrations. FIG. 3. - Results of an in-vitro experiment in the 16-27 hours immediately preceding haemodialysis and during the 14 hours of haemodialysis. Futo Analyzer dialyser unit. The plasma and which gentamicin was dialysed from plasma across a cuprophane membrane (PT 150) in an Auto 
filtration during haemodialysis. However, similar peak plasma levels were obtained when gentamicin was given intravenously immediately before dialysis, suggesting that the size of the distribution volume of gentamicin is not affected by haemodialysis. Further, one patient (Case 2) did not require ultrafiltration during haemodialysis.

One of the major problems of intermittent haemodialysis is infection of the Scribner cannulation site. Those infections due to Gram-negative organisms are notoriously difficult to treat, and often result in loss of the cannula site (Pendras, 1964 ; Pendras and Erickson, 1966 ; Johnson et al., 1966). Previous to the present study, two shunt-site infections due to Ps. pyocyanea resulted in the loss of the shunt site within 48 hours, in spite of treatment with colistin sulphate (Colomycin). In the two patients reported here (Cases 1 and 3) there was clinical evidence of infection of the cannula site characterized by local inflammation, pain, tenderness, and the production of pus from which Ps. pyocyanea was isolated. On treatment with gentamicin there was loss of pain and tenderness, and in Case 1 the cannula continued to function normally until the 24th day, when a mycotic aneurysm ruptured, necessitating removal of the shunt. In Case 3 the cannula continued to function normally until the 26th day, when clotting of the shunt occurred. Declotting was not attempted because of the risk of septicaemia or septic pulmonary embolism; the cannula site was therefore changed.

In all previous studies with gentamicin the intramuscular route of administration had been used. When parenteral administration of any drug is required in patients undergoing intermittent haemodialysis it is advantageous to be able to give the drug intravenously rather than intramuscularly. This obviates the risk of intramuscular haemorrhage, as all such patients are heparinized during dialysis and many are on longterm anticoagulant therapy. An additional advantage of gentamicin is the small volume of fluid per dose $(1-2 \mathrm{ml}$.) that is required. All previous reports in the literature have stressed the lack of local reaction to the intramuscular administration of gentamicin. We have given gentamicin intravenously on 30 occasions in seven patients and two normal subjects. No local or systemic reactions have occurred.

\section{Summary}

Gentamicin was given intravenously to three patients with terminal renal failure treated by intermittent haemodialysis, and to two normal subjects.

Prolonged elevation of plasma gentamicin levels was observed in the patients.

The plasma disappearance rate of gentamicin was significantly increased during haemodialysis by means of a modified Kiil dialyser with cuprophane membranes (PT 150). It has been shown that gentamicin is dialysable from plasma with this membrane.

In patients undergoing twice-weekly haemodialysis on a modified Kiil dialyser with the PT 150 membrane a modified dosage schedule is required; it is suggested that $1 \mathrm{mg}$. of gentamicin per $\mathrm{kg}$. body weight be given intravenously at the end of each dialysis.

We are indebted to Dr. R. Renton and Mr. G. Poulter, of the Nicholas Research Institute Ltd., and to Mr. F. Fennell, of British Schering Ltd., for supplies of Genticin (gentamicin) and for assistance during this study, and to Sister J. M. Storey and the staff of the Renal Unit, Fulham Hospital, for their help.

\section{REFERENCES}

Barber, M., and Waterworth, P. M. (1966). Brit. med. F., 1, 203. Antimicrobial Agents and Chemotherapy, p. 138.

Brayton, R. G., and Louria, D. B. (1964). Arch. intern. Med., 114, 205 Bulger, R. J., Sidell, S., and Kirby, V. . M. M. (1963). Ann. intern. Med., 59, 593.

Curtis, J. R., and de Wardener, H. E. (1967). Israel med. F. In press.

Jao, R. L., and Jackson, G. G. (1963). Antimicrobial Agents and Chemo-

Johnson, W. J., Wagoner, R. D., Hunt, J. C., Mueller, G. J., and Hallenbeck, G. A. (1966). Mayo Clin. Proc., 41, 73.

Klein, J. O., Eickhoff, T. C., and Finland, M. (1964). Amer. F. med. Sci., 248, 528.

Pendras, J. P. (1964). Proceedings of the Working Conference on Chronic Dialysis. University of Washington, Seattle.

- and Erickson, R. V. (1966). Ann. intern. Med., 64, 293.

Rosselet, J. P., et al. (1963). Antimicrobial Agents and Chemotherapy,

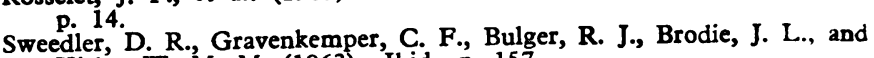
Kirby, W. M. M. (1963). Ibid., p. 157.

Weinstein, M. J., et al. (1963). f. med. pharm. Chem., 6, 463.

\title{
Intrathecal Gentamicin in Treatment of Ventriculitis in Children
}

\author{
R. L. NEWMAN,* M.D.; R. J. HOLT,† M.I.BIOL., F.I.M.L.T.
}

Frit. med. F., 1967, 2, 539-542

The risk of severe infection of the ventricles and meninges by Gram-negative bacteria appears inseparable from extensive neurosurgical procedures. Infection with many strains of Pseudomonas can be successfully treated by the use of intrathecal and intramuscular polymyxin B methane sulphonate (Newman and Stewart, 1964), but a high proportion of the enterobacteriaceae found in these sites are not sensitive to antibiotics suitable for intrathecal therapy.

Reports from many workers (Weinstein et al., 1963 ; Jao and Jackson, 1964 ; Klein et al., 1964) of the unusual antibacterial spectrum and bactericidal effect of gentamicin sulphate suggested that this new antibiotic might be of use in such conditions, and we report here the successful treatment of three patients with meningitis and ventriculitis associated with meningomyeloceles.

\footnotetext{
* Consultant Pathologist, Queen Mary's Hospital for Children, Carshalton,

+Chief Technician, Queen Mary's Hospital for Children, Carshalton,
Surrey.
}

Results of treatment in such a small series must leave many questions unanswered, but the information obtained and the successful outcome in all three cases may be of interest and. we feel, warrant presentation at an early stage. For this reason the laboratory findings are given in some detail.

Gentamicin is derived by ${ }^{*}$ submerged fermentation from a new species of the genus Micromonospora purpurea (Weinstein et al., 1963) and was isolated in the research laboratories of the Schering Corporation, New Jersey. Chemically it consists of two isomeric pseudo-oligosaccharides related to the neomycinparomomycin-kanamycin group of antibiotics (Rosselet et al., 1963 ; Weinstein et al., 1963). Extensive in-vitro tests show that, in addition to activity against many of the common pathogenic Gram-negative bacteria, gentamicin also inhibits all strains of Staphylococcus aureus tested (Barber and Waterworth, 1966). Clinical trials of the antibiotic demonstrate its value in the treatment of urinary infections caused by Gramnegative bacteria (Jao and Jackson, 1964), especially those caused by pseudomonads, and in the treatment of pseudomonas 